\title{
Conscious sedation for interventional neurora- diology: a comparison of midazolam and propofol infusion
}

Pirjo H. Manninen MD FRCPC, Andrew SH Chan MBBS FRCA FRCPC, David Papworth MBBS FFARCS FRCPC

Purpose: The aim of this study was to compare two conscious sedation techniques, midazolam (M) and propofol $(P)$, for interventional neuroradiology by assessment of the incidence of complications and satisfaction scores. Methods: Forty patients were randomized to receive $0.75 \mu \mathrm{ggg}^{-1}$ fentanyl and a $M$ or $P$ bolus followed by an infusion: (M $15 \mu \mathrm{g} \cdot \mathrm{kg}^{-1}+0.5 \mu \mathrm{g} \cdot \mathrm{kg}^{-1} \cdot \mathrm{min}^{-1} ; \mathrm{P} 0.5 \mathrm{mg} \cdot \mathrm{kg}^{-1}+25 \mu \mathrm{g} \cdot \mathrm{kg}^{-1} \mathrm{~min}^{-1}$ ). The incidences of complications and untoward events requiring intervention were documented. These included respiratory depression. excessive pain, inappropriate movements and the inability to examine the patient. The satisfaction of the anaesthetic technique from the perspective of both the neuroradiologist and the patient was scored.

Results: The incidence and types of complications were not different between the two groups. Pain occurred in 12 patients $(6 \mathrm{M}, 6 \mathrm{P})$, inappropriate movements in $17(7 \mathrm{M}, 10 \mathrm{P})$ and respiratory chianges in 10 patients $(2 \mathrm{M}, 8 \mathrm{P})$. Conclusions: Both techniques were satisfactory and the incidence of complications was similar for both groups.

Objectif : Cette étude visait à comparer deux méthodes de sédation consciente, le midazolam (M) et le propofol (P) pour les interventions neuroradiologiques en évaluant l'incidence des complications et le degré de satisfaction.

Méthodes : Quarante patients ont été répartis aléatoirement pour recevoir fentanyl $0.75 \mu \mathrm{g} \cdot \mathrm{kg}^{-1}$ et un bolus de $P$ ou de $M$ suivi par une perfusion: ( $\left.M 15 \mu \mathrm{g}^{\mathrm{kg}} \mathrm{g}^{-1}+0,5 \mu \mathrm{g} \cdot \mathrm{kg}^{-1} \cdot \mathrm{min}^{-1} ; \mathrm{P} 0,5 \mathrm{mg} \cdot \mathrm{kg}^{-1}+25 \mu \mathrm{g} \cdot \mathrm{kg}^{-1} \mathrm{~min}^{-1}\right)$. L'incidence des complications et des effets indésirables nécessitant une intervention a été enregistrée. La dépression respiratoire, la douleur exagérée, les mouvements inappropriés et l'incapacité de subir l'examen étaient considérés comme indésirables. Un score équivalent au degré de satisfaction à l'égard de la technique anesthésique était attribué en tenant compte du point de vue de l'anesthésiste et de celui du radiologiste.

Résultats : Lincidence et le type de complication ne différaient pas entre les deux groupes. La douleur a été rapporté par 12 patients $(6 \mathrm{M}, 6 \mathrm{P})$, des mouvements inappropriés chez 17 patients $(7 \mathrm{M}, 10 \mathrm{P})$ et des altérations de la respiration chez 10 patients $(2 \mathrm{M}, 8 \mathrm{P})$.

Conclusion : Les deux techniques ont été satisfaisantes et l'incidence des complications était la même dans les deux groupes.

From the Department of Anaesthesia, The Toronto Hospital, Western Division, University of Toronto, 399 Bathurst Street, Toronto, Ontario, Canada, M5T 2S8

Address Correspondence to: Dr. Pirjo $\mathrm{H}$ Manninen.

Accepted for publication August 30, 1996. 


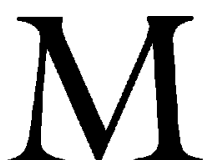

ANY patients with intracranial vascular lesions undergo investigational or therapeutic interventional neuroradiological (INR) procedures. These include embolization of arterial venous malformations and vascular tumours, coiling of aneurysms, and balloon occlusion of the arterial supply of these lesions ${ }^{1-5}$ The procedures are not intrinsically painful but are often prolonged and require relative immobility throughout. Communication with the patient is usually maintained in order to monitor cerebral function during critical periods. The anaesthetic management of these patients includes administration of sedative and/or analgesic agents. There is little information about the ideal anaesthetic agents for these procedures. The purpose of this study was to compare two techniques of conscious sedation, the infusion of midazolam and propofol, to ascertain whether the newer agent, propofol, had any advantage over midazolam. We compared the incidence of complications related to anaesthesia and to the procedure, and the satisfaction of the anaesthetic technique from the perspective of the neuroradiologist and the patient.

\section{Methods}

After approval from the institutional ethics review board, informed consent was obtained from 40 patients scheduled for INR procedures. Patients were randomly allotted into two groups to receive either midazolam (group 1) or propofol (group 2). The neuroradiologist and patient were unaware of the agent used. Postoperative evaluation was performed by an investigator not involved in the care of the patient. Patients received no preoperative medication before coming to the radiology suite. On arrival, they were positioned comfortably on the radiology table and an infusion with normal saline was started. All patients were monitored with a noninvasive blood pressure cuff, ECG, pulse oximeter and end-tidal capnogram via nasal prongs or face mask which also supplied the patient with continuous supplemental oxygen. All patients received $15 \mu \mathrm{g} \cdot \mathrm{kg}^{-1}$ midazolam and 0.75 $\mu \mathrm{g} \cdot \mathrm{kg}^{-1}$ fentanyl $i v$ before the access area was prepared and draped and scout films taken. Just before the infiltration of the access area by the neuroradiologist with a long acting local anaesthetic agent (bupivacaine), conscious sedation was started. Group 1 patients received an additional dose of $7.5-15 \mu \mathrm{g} \cdot \mathrm{kg}^{-1}$ midazolam, if required, followed by an infusion at 0.5 $\mu \mathrm{g} \cdot \mathrm{kg}^{-1} \cdot \mathrm{min}^{-1}$. Those in group 2 received a bolus of $0.25-0.5 \mathrm{mg} \cdot \mathrm{kg}^{-1}$ propofol followed by an infusion of propofol, $25 \mu \mathrm{g} \cdot \mathrm{kg}^{-1} \cdot \mathrm{min}^{-1}$. Infusion rates were adjusted by increasing or decreasing the rate to maintain an objective conscious sedation level of mild sedation, which was defined as the patient resting comfortably, but easily arousable and alert to obey commands. The infusion was stopped during critical periods such as during the occlusion of a major vessel or immediately following embolization to allow for precise neurological examination. Fentanyl $0.5 \mu \mathrm{g} \cdot \mathrm{kg}^{-1}$ or $15 \mu \mathrm{g} \cdot \mathrm{kg}^{-1}$ droperidol was administered as needed for excessive pain or nausea and vomiting, respectively. Neurological assessment of the level of consciousness, (whether patient was fully awake and orientated, drowsy and/or confused, or unresponsive) and of appropriate centres such as speech, memory, and motor and sensory function were tested intermittently throughout the procedure and repeatedly during critical events. Cardiovascular (heart rate and blood pressure $)$ and respiratory $\left(\mathrm{SpO}_{2}, \mathrm{P}_{\mathrm{ET}} \mathrm{CO}_{2}\right.$ and respiratory rate) variables were continuously monitored. All patients received heparin (100 units $\cdot \mathrm{kg}^{-1}$ ) prior to embolization or occlusion of an artery. At the end, the action of heparin was reversed with $0.5 \mathrm{mg} \cdot \mathrm{kg}^{-1}$ protamine, unless the femoral catheters were left in situ.

The anxiety score of the patient was noted on arrival in the radiology suite. This was graded as " 0 " for none or minimal signs of anxiety such as agitation, sweating, tearing or verbal expression by the patient. A score of "l" was moderate and "2" for severe anxiety. All complications or undesirable events requiring intervention were documented. Respiratory variables included oxygen desaturation $\left(\mathrm{SpO}_{2}<90 \%\right)$, hypercarbia $\left(\mathrm{P}_{\mathrm{ET}} \mathrm{CO}_{2}>45 \mathrm{mmHg}\right)$, respiratory rate $(<8 \mathrm{bpm})$, airway obstruction, and snoring. Other events noted were excessive pain or distress, restlessness or inappropriate movements, excessive sedation, loss of cooperation by the patient and the inability to perform neurological testing. Also noted were any "reruns" that were required due to patient inability to lie still during angiograms and especially during the super selective films. The other major complications noted were the cessation of the procedure or the need for induction of general anaesthesia. All technical and procedure related complications were documented.

At the conclusion of the procedure the neuroradiologist was asked to give a visual analogue score (VAS) on a scale from 0 to 10 , where " 0 " referred to cases where the procedure had to be abandoned or general anaesthesia induced due to inappropriate sedation, and "10" referred to cases where the patient was fully cooperative in all respects. One hour after arrival in the recovery room or in the neurointensive care unit, the patient was asked to state a VAS for overall satisfaction with their anaesthetic management. Their satisfaction was assessed by questioning the patients 
about recall of their comfort level, of painful or unpleasant events during the procedure. They were then asked to grade the VAS from " 0 " being the worst experience they have ever had to " 10 " being a good experience and they would undergo it again if need be. Any complications including unexpected neurological deficits were noted. Patients were assessed again the following day.

Statistical analysis was performed by Student's T test and chi square testing, where appropriate. Results are given as mean \pm standard deviation. $P<0.05$ was considered significant.

\section{Results}

Forty patients were studied, 20 in each group. There were no differences between the two groups with respect to demographics, and the types of procedures performed (Table I). The anxiety scores prior to the procedure were not different (midazolam $1.2 \pm 0.8$, propofol $0.9 \pm 0.7$ ). The VAS scores for both neuroradiologist (midazolam $8.9 \pm 1.1$, propofol $9.0 \pm 1.2$ ), and patients (midazolam $8.6 \pm 2.3$, propofol $9.2 \pm 1.0$ ) showed satisfaction with the anaesthetic techniques and were not different. The doses of the anaesthetic agents required are shown in Table II. There was a tendency for patients in the midazolam group to

TABLE I Demographics

\begin{tabular}{lll}
\hline & Midazolam & Propofol \\
\hline Age (yr) & $44 \pm 18$ & $48 \pm 18$ \\
Weight (kg) & $70 \pm 13$ & $71 \pm 13$ \\
Sex (M:F) & $12: 8$ & $9: 11$ \\
LESION & & \\
AVM (n) & 12 & 12 \\
Tumour (n) & 5 & 7 \\
Aneurysm (n) & 3 & 1 \\
PROCEDURE & & \\
Duration (min) & $108 \pm 46$ & $129 \pm 63$ \\
Embolized (n) & 9 & 13 \\
Attempted embolization (n) & 5 & 3 \\
Test occlusion (n) & 6 & 4 \\
\hline
\end{tabular}

Values are mean $\pm S D$

$\mathrm{n}=$ number of patients

TABLE II Dosage of Anaesthetic Agents

\begin{tabular}{lll}
\hline & Midazolam & Propofol \\
\hline Total Study Agent & & \\
$\mathrm{mg}$ & $6.7 \pm 5.1$ & $263 \pm 124$ \\
$\mathrm{mg} \cdot \mathrm{kg}^{-1}$ & $0.08 \pm 0.06$ & $3.8 \pm 1.7$ \\
Fentanyl & & \\
$\mu \mathrm{g}$ & $92 \pm 50$ & $70 \pm 26$ \\
$\mu \mathrm{g} \cdot \mathrm{kg}^{-1}$ & $1.3 \pm 0.74$ & $1.0 \pm 0.42$ \\
\hline
\end{tabular}

Values are mean $\pm S D$ require more fentanyl but this was not statistically significant. Two patients in each group received droperi$\mathrm{dol}$ at the beginning of the procedure in anticipation of nausea.

The incidence and types of complications that occurred were not different between the two groups (Table III). The percentage of patients in each group who had at least one complication was not different (midazolam $40 \%$, propofol $62 \%$ ). There was no difference in the number of different types of complications per patient in each group (midazolam $0.6 \pm 0.8$, propofol $0.9 \pm 0.9$ ). Twelve patients complained of pain or moderate discomfort, requiring additional analgesia, five during the placement of the catheters and five patients complained of a hot sensation or headache during embolization. Two patients developed an uncomfortable flushing sensation from the protamine. One patient in the midazolam group developed severe headache and nausea after $30 \mathrm{~min}$. of balloon occlusion of the carotid artery in preparation for surgical treatment of her tumour. This pain continued for several hours despite release of the occlusion. One patient in the midazolam group became uncooperative two hours after the start of the procedure. Because his lesion was a very difficult AVM to embolize, the procedure was abandoned with the plan to repeat embolization with general anaesthesia at another time. No patient required induction of general anaesthesia during the procedure. Inappropriate movements or episodes of restlessness during critical periods occurred in 17 patients. In all patients, but three, this happened only once. These episodes interfered with the angiograms (requiring reruns) in three patients. Oversedation lead to respiratory changes in 10 patients. There was only one technical complication in this series, the loss of the tip of a catheter in the patient (midazolam group), but there were no clinical sequelae.

Since there was little information regarding anaesthetic techniques during INR, the initial analysis of sample size for this study was based on previous work which compared the effectiveness of sedation with

TABLE III Complications (Number of Patients)

\begin{tabular}{lll}
\hline & Midazolam & Propofol \\
\hline Pain & 6 & 6 \\
Nausea & 1 & 1 \\
Uncooperative & 2 & 0 \\
Inappropriate movements & 7 & 10 \\
Reruns & 1 & 2 \\
Respiratory changes & & \\
Oversedation & 2 & 8 \\
Neurological & 0 & 0 \\
\hline
\end{tabular}

* Respiratory changes $=$ snoring, obstruction, $\mathrm{S}_{\mathrm{P}} \mathrm{O}_{2}<90 \%$, respiratory rate $<8$ bpm 
midazolam and propofol. We were unable to detect any differences between midazolam and propofol, but the power of our study was inadequate to prove that the groups did not differ in all areas. Power analysis calculated on the incidence of complications, using $\alpha$ of 0.05 showed that the power of our study was only $55 \%$. To obtain a power of $80 \%, 48$ patients would be required in each group.

The immediate outcome of the procedure was classified as embolized if the intended procedure for that day was successful (Table I). Attempted procedures were the cases where the lesion was not embolized due to the nature of the lesion or anatomical reasons making it technically impossible to do. Ten patients underwent a trial occlusion of the carotid artery with an inflated balloon for $30 \mathrm{~min}$. In three patients the balloons were left in place for permanent treatment of the aneurysm. We were unable to perform follow up assessments on most patients the next day as they were transferred to other hospitals, sent home, or to surgery the same or the next morning. Also, many patients underwent definitive treatment of their lesion (surgery, radiotherapy) at other institutions.

\section{Discussion}

Many INR procedures in adults do not require general anaesthesia and the usual approach has been to provide light intravenous sedation with careful monitoring. ${ }^{6-9}$ The goals of conscious sedation anaesthesia are alleviation of pain, discomfort, anxiolysis, and provision of patient immobility. The procedures generally are not painful but discomfort and pain may occur at certain times such as the insertion of the catheters during embolization or the "hot flush" that occurs during the injection of contrast media into the cerebral arteries. Also, the patient will experience discomfort from lying still on an uncomfortable table. Patient immobility is extremely important particularly during the finer angiography, and embolization. Anxiolysis is required as the procedure may be very stressful to the patient with the knowledge that there is a risk of stroke, or even death. On the other hand, the patient's cooperation is frequently required for neurological assessment, especially during periods of critical events such as balloon occlusion of a major vessel, or immediately after the embolization of an eloquent area.

Conscious sedation may be defined as a minimally depressed level of consciousness, where the patient is able to maintain their airway and respond appropriately to commands. In our study, we did not measure levels of sedation but rather counted untoward events (respiratory changes, excessive pain, restlessness, or the inability to respond to commands) as complications. To achieve appropriate levels of conscious sedation a variety of anaesthetic agents and regimens is possible and has been used. ${ }^{6-8} \mathrm{We}$ chose to study an infusion technique using two commonly used drugs, midazolam and propofol, and supplemental fentanyl. We aimed our dosages to obtain a level of mild sedation which we defined as a state where the patient is calm and tranquil, but easily aroused. Midazolam was chosen because of its widespread use as a sedative agent in many areas of anaesthesia, surgery and the intensive care unit and propofol was selected because of its increasing use for similar purposes. Midazolam has amnesic, anxiolytic, sedative and anticonvulsive properties. ${ }^{10}$ Because of its rapid elimination midazolam can be easily administered by continuous iv infusion at a rate of 0.5 to $1.0 \mu \mathrm{g} \cdot \mathrm{kg}^{-1} \cdot \mathrm{min}^{-1}{ }^{11-13} \mathrm{We}$ chose the lower value as we wanted our patients to be relatively alert. Propofol is a newer agent that has similar properties and uses to midazolam. ${ }^{14,15}$ The potential benefits of propofol for sedation when compared with midazolam include more rapid titration of a level of sedation and faster return of clear-headedness. ${ }^{11,12,16,17}$ The rapid recovery is important in INR as the patients need to interact for neurological assessment at many points during the procedure. The recommended dose for sedation with propofol is 25 to $75 \mu \mathrm{g} \cdot \mathrm{kg}^{-1} \cdot \mathrm{min}^{-1}$ following a loading dose of $0.5 \mathrm{mg} \cdot \mathrm{kg}^{-1} \cdot{ }^{13}$ The dosage levels of both agents that we used have been shown to produce similar levels of conscious sedation. ${ }^{11,13,16}$ An analgesic was added to provide pain relief from the more painful parts of the procedure and also to decrease the discomfort from lying on a hard table. Fentanyl was chosen as the analgesic because of its effectiveness, general acceptance and short duration of action. An antiemetic, droperidol, was available for nausea, but was not required in any of these patients during the procedure. Both groups were given similar basal sedation of midazolam and fentanyl in the radiology suite to help with the initial anxiety and discomfort from positioning. It was not possible to standardize a premedication routine before arrival in the radiology suite as our patients came through many different routes such as same day admission or from other hospitals. There was no difference in the amount of fentanyl required between the two groups.

Complications may occur from the chosen anaesthetic agents and techniques, such as oversedation or excessive pain. Patients may also become uncooperative or disinhibited due to the agents used. In our series, 17 patients had episodes of restlessness or inappropriate movement at critical times. These episodes 
mostly happened only once in each patient and reruns were only required three times. These events may result from inadequate analgesia or anxiolysis or may also occur when a patient is oversedated and fails to follow commands. The incidence of the anaesthetic related complications was not great and there was no difference between the two groups.

There are a number of complications that may result from the technical aspects of INR procedures, the two most serious are cerebral infarction and haemorrhage. Infarction may occur from thrombosis, or misplacement or occlusion of a vessel by a catheter, balloon or embolic material. Haemorrhage may occur from the rupture of a vessel or of the lesion itself. Careful neurological testing may give the first clue to the development of ischaemia. This will allow for rapid cessation of the procedure and/or treatment of the patient. The incidence of serious complications, such as permanent neurological deficits, in these procedures varies from 4 to $27 \%{ }^{3-5,18}$ In this series there were no major complications.

The tolerance of occlusion of a major artery such as the internal carotid for occlusion during surgery and occasionally for the permanent treatment of an aneurysm is tested usually for $20-30 \mathrm{~min}$. In one patient in our series this was performed in preparation for the intraoperative trapping of a giant aneurysm. With this patient we used induced hypotension with sodium nitroprusside and esmolol to achieve a mean pressure of $50-60 \mathrm{mmHg}$, which the patient tolerated.

The satisfaction of the anaesthetic techniques, as evaluated by the neuroradiologist, showed no difference between propofol and midazolam. In the patient satisfaction scores there was again no difference between propofol or midazolam. However, we were only able to evaluate the immediate score, and did not perform follow-up assessments.

In conclusion, we found that both techniques of conscious sedation, midazolam and propofol with fentanyl were satisfactory for INR procedures where patient cooperation is required.

\section{Acknowledgments}

The authors wish to thank the neuroradiologists, all the staff of Neuroradiology and Dr. C F Kearns for all their assistance with this study.

\section{References}

1 Debrun G, Vinuela F, Fox A, Drake CG. Embolization of cerebral arteriovenous malformations with bucrylate. J Neurosurg 1982; 56: 615-27.

2 Eskridge JM. Interventional neuroradiology. Radiology 1989; 172: 991-1006.
3 Viuela F, Dion JE, Duckwiler G, et al. Combined endovascular embolization and surgery in the management of cerebral arteriovenous malformations: experience with 101 cases. J Neurosurg 1991; 75: 856-64.

4 Jafar J, Davis AJ, Berenstein A, Choi IS, Kupersmith $M J$. The effect of embolization with $\mathrm{N}$ - butyl cyanoacrylate prior to surgical resection of cerebral arteriovenous malformations. J Neurosurg 1993; 78: 60-9.

5 Lewis AI, Tomsick TA, Tew JM Jr. Management of 100 consecutive direct carotid-cavernous fistulas: results of treatment with detachable balloons. Neurosurgery 1995; 36: 239-45.

6 O'Mahony BJ, Bolsin SNC. Anaesthesia for closed embolisation of cerebral arteriovenous malformations. Anaesth Intensive Care 1988; 16: 318-23.

7 Young WL, Pile-Spellman J: Anesthetic considerations for interventional neuroradiology. Anesthesiology 1994; 80: 427-56.

8 Manninen PH, Gignac EM, Gelb AW, Lownie SP. Anesthesia for interventional neuroradiology. J Clin Anesth 1995; 7: 448-52.

9 Luessenhop $A J$. Interventional Neuroradiology: a neurosurgeon's perspective. AJNR Am J Neuroradiol 1990; 11: 625-9.

10 Reves JG. Fragen RJ. Vinik HR, Greenblatt DJ. Midazolam: pharmacology and uses, Anesthesiology 1985; 62: 310-24.

11 Wilson E, Dapid A, Mackenzie N, Grant IS. Sedation during spinal anaesthesia: comparison of propofol and midazolam. Br J Anaesth 1990; 64: 48-52.

12 Kestin IG, Harvey PB, Nixon C. Psychomotor recovery after three methods of sedation during spinal anaesthesia. Br J Anaesth 1990; 64: 675-81.

13 Pace NA, Victory RA, White PF. Anesthetic infusion techniques - how to do it. J Clin Anesth 1992; 4 : \$45-52.

14 Mackenzie N. Grant IS. Propofol for intravenous sedation. Anaesthesia 1987; 42: 3-6.

15 Smith I, Monk TG, White PF, Ding $Y$. Propofol infusion during regional anesthesia: sedative, amnestic, and anxiolytic properties. Anesth Analg 1994; 79: 313-9.

16 Fanard L, Van Steenberge A. Demeire $X$, van der Puyl $F$. Comparison between propofol and midazolam as sedative agents for surgery under regional anaesthesia. Anaesthesia 1988; 43 (Suppl): 87-9.

17 Patterson KW, Casey PB, Murray JP. O'Boyle CA, Cunningham AJ. Propofol sedation for outpatient upper gastrointestinal endoscopy: comparison with midazolam. Br J Anaesth 1991; 67: 108-11.

18 Lownie SP. Clinical and technical complications of endovascular therapy in the central nervous system. Seminars in Interventional Radiology 1993; 10: 243-53. 